\title{
Overcoming Distance: Video-Conferencing as a Clinical and Educational Tool Among Surgeons
}

\author{
Knut Magne Augestad · Rolv Ole Lindsetmo
}

Published online: 22 April 2009

(c) The Author(s) 2009. This article is published with open access at Springerlink.com

\begin{abstract}
Background Since the 1960s, there has been substantial development in the uses of video-conferencing (VC) among medical personnel, including surgeons who have adopted the technology.

Methods A report on our own experience with VC was combined with a comprehensive PubMed search with the key words telepresence, video-conferencing, video-teleconferencing, telementoring and surgery, trauma, followup, education, and multidisciplinary teams. A search through two peer-reviewed telemedicine journals-Journal of Telemedicine and Telecare and Telemedicine and $e$ Health Journal-and references of all included papers and identified additional reports was conducted.

Results A total of 517 articles were identified with 51 relevant manuscripts, which included the key phrases. VC is widely used among surgeons for telementoring surgical procedures and in trauma and emergency medicine. Furthermore, $\mathrm{VC}$ is widely used by multidisciplinary teams and for the follow-up of patients after surgery.

Conclusions VC is a common clinical tool for surgeons and provides a great opportunity to alter surgical practice and to offer patients the best expertise in surgical treatment despite long distances, especially in rural areas.
\end{abstract}

\footnotetext{
K. M. Augestad ( $\square)$

Norwegian Centre for Telemedicine, Troms $\varnothing$, Norway

e-mail: knut.magne.augestad@telemed.no
}

K. M. Augestad · R. O. Lindsetmo

Department of Gastrointestinal Surgery, University Hospital

of North Norway, Troms $\varnothing$, Norway

R. O. Lindsetmo

Institute of Clinical Medicine, University of Troms $\varnothing$,

Troms $\varnothing$, Norway

\section{Introduction}

In 1962, Dr. Michael Ellis DeBakey pioneered the field of telemedicine with the first VC demonstration of open-heart surgery to be transmitted overseas by satellite. Medical staff in Geneva were able to view an aortic valve replacement being performed at The Methodist Hospital in Houston, Texas [1, 2].

Since the 1960s, there has been substantial development in the uses of VC among medical personnel, including surgeons [3]. In recent years, the cost of VC equipment has become less expensive, and advanced technical skills are not required to use the system. Therefore, new applications of VC are emerging, such as surgical telementoring, trauma and emergency medicine, postoperative follow-up of patients, education of surgeons, and multidisciplinary team meetings.

In 2004, the Society of American Gastrointestinal and Endoscopic Surgeons (SAGES) presented their definitions of telemedicine [4]. VC is defined as a real-time, live, interactive program in which one set of participants are at one or more locations and the other set of participants are at another location. The VC permits interaction, including audio and/or video, and possibly other modalities, between at least two sites [4]. A similar definition is used in the Telemedicine Journal and e-Health [3].

This article presents the current status of VC as a clinical tool among surgeons. It is based on a literature review and our own experience.

\section{Materials and methods}

This review is based on a PubMed search using EndNote X1 (San Francisco, CA, USA) for relevant publications 
published through November 2008 as well as the experience from the Norwegian National Centre of Telemedicine in the use of VC. The search terms were telepresence, video-conferencing, video-teleconferencing, telementoring; and they were combined with the search terms surgery, trauma, follow-up, education, and multidisciplinary teams. A total of 517 original research hits yielded 51 manuscripts. We also systematically searched the reference list of included studies and the two telemedicine journals (Journal of Telemedicine and Telecare and Telemedicine and e-Health Journal). In addition, eight publications from the University Hospital North Norway and Norwegian National Centre for Telemedicine were included.

The two authors independently reviewed the titles, index terms, and abstracts of the identified references and rated each paper as "potentially relevant" or "not relevant."

We used the definition of VC described by Telemedicine Journal and e-Health and SAGES [3, 4], and disagreements of inclusion were resolved with discussion.

\section{Results}

\section{Technical aspects}

The International Telecommunication Union (ITU) [5] has defined several technical standards for VC equipment. These standards determine whether VC equipment from different manufacturers (e.g., Tandberg, Polycom, Sony, Microsoft, Aethra, among others) can communicate and handle data transport. In addition, ITU has defined several subgroup standards, such as sound, video, parallel video streams, and data encryption. The latter is important for patient security, confidentiality, and privacy [3]. Four technical solutions for data transmission during a VC are possible: satellite communication, Internet Protocol (IP)based communication, Integrated Services Digital Network (ISDN), and third-generation (3G) mobile phones (Table 1).

\section{VC via satellite}

Conducting VC via satellite provides a portable method and can be used anywhere in the world provided the necessary satellite coverage for that area is available. This makes the equipment especially suitable for use in disasters and in rural areas with poor infrastructure. However, the cost is high-for the equipment itself (Tandberg 30 000 USD) and for the rental to access a satellite (500 $1000 \mathrm{USD} / \mathrm{month})$. There is usually considerable latency in both video and audio (1-2 seconds) compared to VC via IP.

\section{VC via IP}

The use of IP for VC has several advantages. In closed networks, such as the Norwegian Healthcare Network, there is usually minimal time latency, and the signal quality is good. However, if the open Internet is used, there are no guarantees of quality of service, as it is dependent on the amount of traffic on the Internet. There is usually a reasonable price for line rental.

\section{VC via ISDN}

ISDN use for VC has seen a reduction in the Western world after introduction of the $3 \mathrm{G}$ mobile phone.

\section{$V C$ via $3 G$ mobile phone}

Using a $3 \mathrm{G}$ mobile phone for $\mathrm{VC}$ is widely used in the medical community [6-8]. Services include wide-area wireless voice telephony, video calls, and broadband wireless data, all in a mobile environment. It is easily accessible for a reasonable price on the commercial market. The $3 \mathrm{G}$ phone method is dependent on special features in the mobile telecommunication network. Although such features are not available in all countries, $60 \%$ of the population of South Africa has access to $3 \mathrm{G}$ bandwidth; and in Nigeria and Uganda $90 \%$ of the population has access to 3G bandwidth [9]. There are, however, several disadvantages. There is usually a small display, and the quality of the video is poorer than standard video equipment. The camera lenses are usually of lower quality than standard VC equipment. The $3 \mathrm{G}$ mobile phones use separate communication standards and cannot communicate with traditional VC equipment. Data encryption is not possible with a $3 \mathrm{G}$ mobile phone.

\section{VC for surgical education}

Video-conferencing is widely used for educational purposes by surgeons throughout the world. The rapid evolution of scientific and technical knowledge in surgery explains the demand by surgeons and surgical students for easy and full access to high-quality information [10].

In remote areas, $\mathrm{VC}$ has proven to be an effective educational tool. In Norway, graduate education in orthodontics (surgical treatment of irregularities of teeth and the jaw) has so far been available as a full-time 3-year program at the universities in Oslo and Bergen only. To make training in orthodontics more accessible in other parts of the country, a pilot project supported by the Ministry of Health was established in 2002 [11]. The participating institutions were the Public Dental Health Service in Troms $\varnothing$, University of Oslo, University of Troms $\varnothing$, and the 


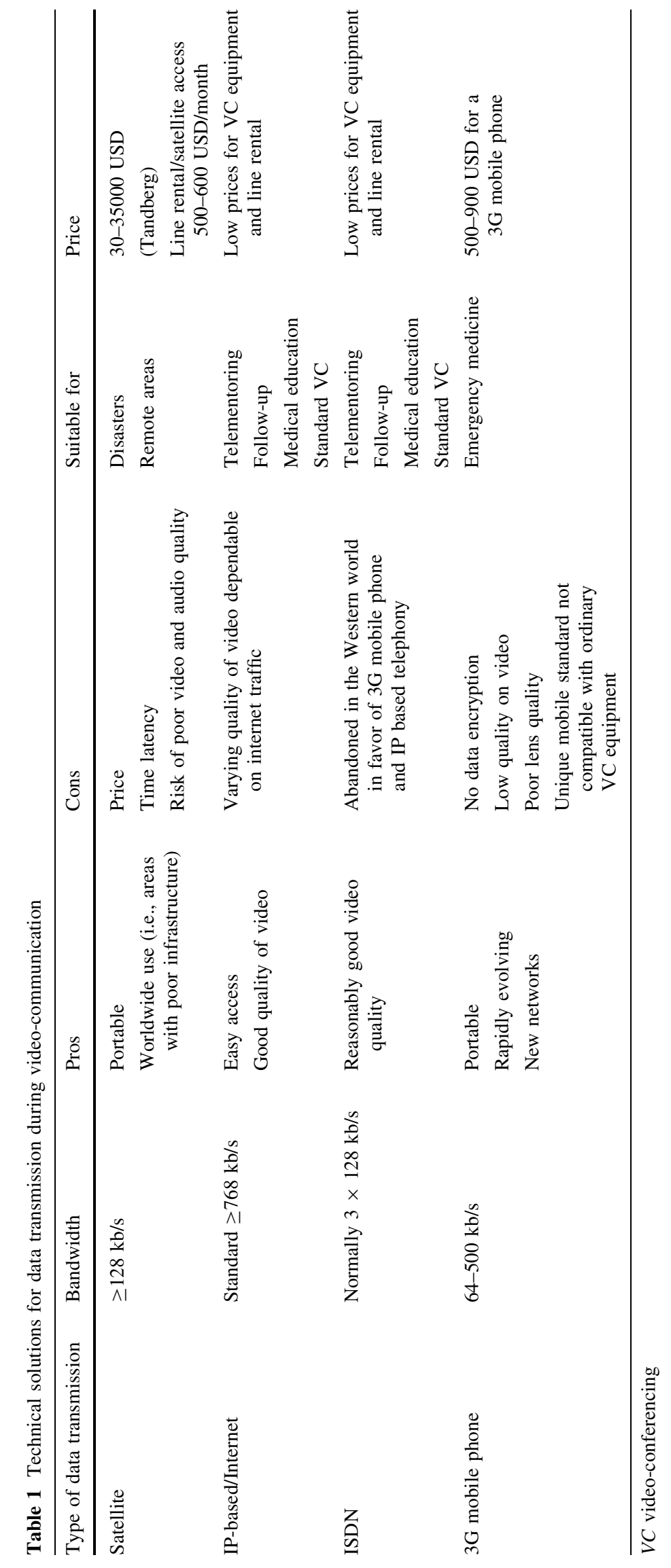


Norwegian Centre for Telemedicine. The basic elements in the training program were joint courses at the University of Oslo (e.g., laboratory courses, hands-on courses) (about 8\% of the curriculum); treatment of patients at the University Hospital in Troms $\varnothing$ (about $45 \%$ of the curriculum); and academic training such as seminars, lectures, and courses in "a virtual classroom" (about $45 \%$ of the curriculum). The virtual classroom included daily sessions with VC of seminars, courses, or lectures and Intranet access for distribution of teaching material and contact between teachers and students at the university hospitals in Troms $\varnothing$ and Oslo, 900 miles apart. The goals for the project were to train orthodontists who are most likely to stay in northern Norway, provide the new dentist education in Troms $\varnothing$ with teachers for undergraduate students, and evaluate whether this concept could serve as a model for training in other disciplines and hospitals. After 3 years of education and practical training, a joint examination with an external examiner was arranged at the University of Oslo, which the students successfully passed [11].

An Australian study sought to address this issue by providing synchronous tutorials in pediatric surgery using $\mathrm{VC}$ at two rural sites with the tutor located at a metropolitan pediatric clinical school. VC surgical tutorials were highly valued by graduate medical students as an educational method [12].

There is a dire shortage of medical specialists, and many countries lack suitably qualified doctors to train medical specialists. VC offers the opportunity to share scarce human resources. A successful educational VC project was recently reported from Africa, where the shortage of pediatric surgeons is acute [13].

Telemedicine, using interactive $\mathrm{VC}$, is an effective method for didactic lectures in a surgical clerkship. This technology allows students to receive interactive lectures at remote clinical sites without the need to travel long distances [14]. Similar results have been reported from both industrialized and developing countries [15-20].

\section{VC in multidisciplinary teams}

Bringing together multiple experts to focus as a group on a single patient is now a formidable organizational and logistical challenge. With VC, discussion of a series of patients among a broad range of experts is possible across vast distances, resulting in a level of consultation at a cost otherwise not possible. Multidisciplinary teams (MDTs) should improve coordination, communication, and decision-making between health care team members and patients and hopefully produce more positive outcomes. $\mathrm{VC}$, as a tool to improve communication between different levels of health care, has been described from a number of surgical subspecialties [21, 22].
After introduction of an MDT approach in cancer care, VC has also been introduced as a clinical tool in this setting. Norum and Jordhoy published a study demonstrating the feasibility of $\mathrm{VC}$ for clinical and educational support between specialists at the University Hospital of North Norway and colleagues at the oncology and palliative care unit of the Nordland Hospital in Bodø, 300 miles apart. VC was a success in the education and clinical case discussion with the remote oncologists in Bodø. During a 12-month period, 32 VCs were performed; the study demonstrated that telemedicine can be used to incorporate a remote palliative care unit into a university department [23].

Dickson-Witmer et al. recently published a study of a VC network to discuss prospective patient management issues. Information was shared on a weekly basis with discussion of treatment decisions and diagnostic procedures. The VC led to an increase in National Cancer Institute treatment and accrual to cancer control clinical trials [24].

Three studies have published experience from breast cancer surgeons participating in MDTs. The VC was compared with the previous face-to-face clinical meetings through questionnaires, attendance, number of cases discussed, and anthropological analysis. Multidisciplinary case discussion can thus be facilitated by VC $[25,26]$.

Kunkler et al. proposed a comprehensive methodology to assess the clinical and economic effectiveness of $\mathrm{VC}$ in MDTs [27]. This methodology was later tested in a randomized breast cancer trial [28], where 473 MDT patient discussions in two district general hospitals were cluster randomized to the intervention of telemedicine linkage to breast specialists in a cancer center or to the control group of "in-person" meetings. VC was cost-effective, and breast cancer MDTs have clinical effectiveness similar to that of standard "in-person" meetings [28].

There is a shortage of thoracic surgeons in the United Kingdom, and MDT meetings by VC were therefore introduced. The telemedicine meetings saved more than three working weeks of thoracic surgical time during the year [29].

The MDT meetings are used for establishing diagnoses; for tumor, node, and metastasis (TNM) classification; and for treating patients with head and neck tumors. In a Swedish study, telemedicine was introduced to link the regional hospital to two of the three district general hospitals. The conclusion was that costs could be saved by carrying out MDT meetings by means of telemedicine instead of face-to-face meetings [30].

A recent report on cancer services in Wales recommended an integrated cancer service with $\mathrm{VC}$ as a clinical tool. Regular MDT meetings reduced the need for patients to travel. They also increased access to expert opinion and reduced the delay in implementing treatment [31]. 


\section{$\mathrm{VC}$ in trauma and emergency medicine}

Management of trauma patients requires fast, definitive, precise care as well as major resources and continuous expertise. Most trauma centers around the world are concentrated in urban settings; consequently, most of the world's population is not covered by specialized trauma systems. Telemedicine for trauma and emergency management is therefore emerging as a new frontier and is evolving as an integrated part of trauma care in modern trauma practice. So far, the use of VC and mentoring over distance has been the cornerstone of the present technologic solutions [32]. In emergency situations, there are a limited number of medical specialities on duty in a local hospital. A possibility to improve the accessibility of emergency specialists is to communicate over distance in the emergency situation.

A VC system, configured and modified for this purpose, was implemented at Longyearbyen Hospital Spitsbergen and the Dispatch Centre at University Hospital of North Norway some 600 miles apart. The technical solution was based on a high-capacity fiberoptic cable between the island and mainland Norway, provided by the National Aeronautics and Space Administration (NASA) during the construction of Svalbard Satellite Station (SvalSat) [33]. In the trauma room in Spitsbergen, a VC unit with an oversight camera and a camera on the ceiling, which was able to zoom and change angles, were installed (Fig. 1). This

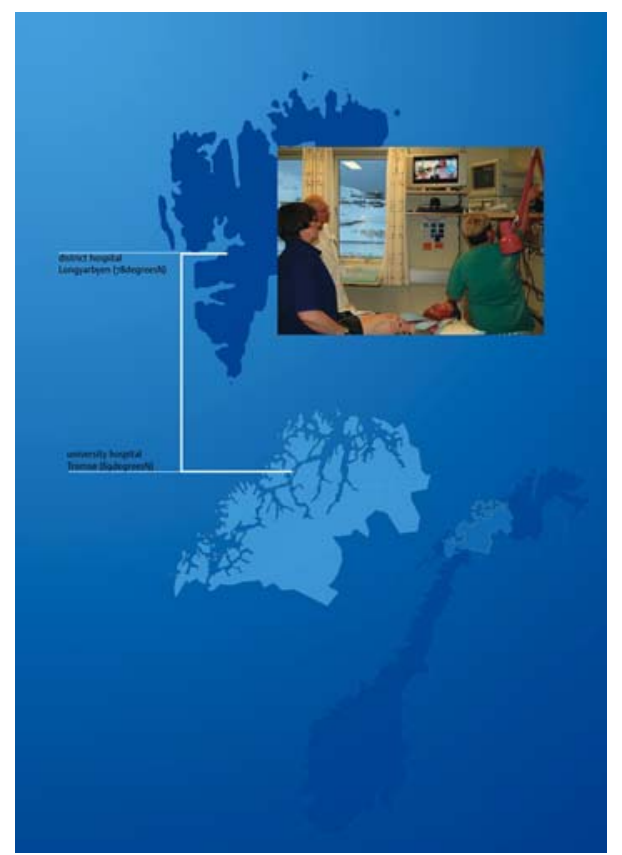

Fig. 1 Trauma mentoring. The trauma surgeons are located at the university hospital in northern Norway 600 miles away and have remote control of two cameras in the trauma room in Spitsbergen (one camera at the wall and one camera directly above the patient)

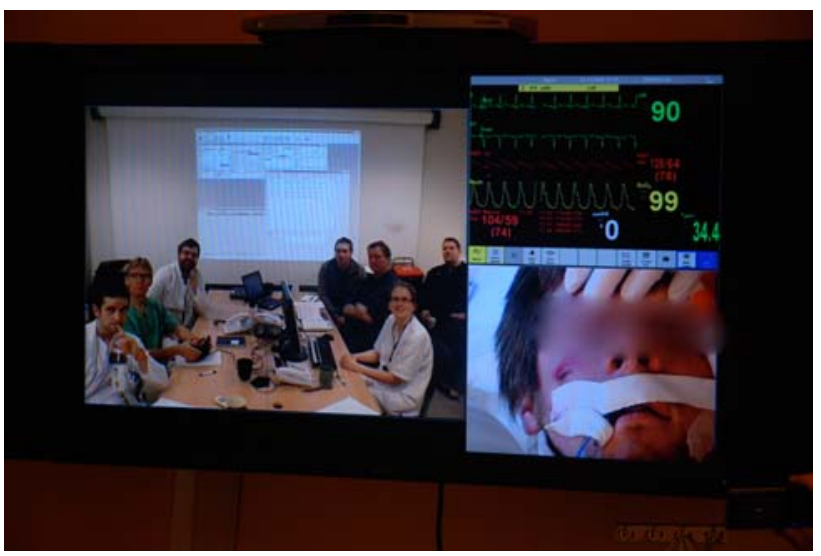

Fig. 2 Dispatch center at the university hospital. Screen setup, including a view of the patient, biological parameters, and eventually radiologic images, is performed at the dispatch center

VC unit was connected with the University Hospital trauma VC room. In this $\mathrm{VC}$ room, the trauma surgeons have remote control of the cameras in Spitsbergen (Fig. 2), and biological parameters are shown on a separate screen. From Troms $\varnothing$ the trauma surgeons can follow the development of the situation and together with the local team decide priorities, treatment, procedures, transport, and need for support. During the project period, much of the focus on the testing was on team communication and interaction. The project was intended to improve the communication between the medical staff at the local hospital and the trauma surgeons in the university hospital by using VC. The study focused on the possible benefits of VC. Are the decisions quicker and more correct? Does the communication improve cooperation and local competence?

To describe the advantages and disadvantages of communicating through the system, we selected a limited number of cases tested by the emergency teams in the local hospital in Longyearbyen. On the specialist side, the clinical emergency specialists responded to problems as they arose. To measure the value of $\mathrm{VC}$, we compared it to the traditional use of telephone communication. The method of testing was observation and interview of both local teams and specialists at the Dispatch Centre. Preliminary results suggest that this $\mathrm{VC}$ solution improves the interaction between the two medical teams and benefits certain groups of patients. Clinical testing and experience is needed to find the right kind of use. It is also necessary to establish routines for organization and communication [34].

Recently a U.S.-based study [35] showed that telemedicine significantly improved evaluation and management of trauma patients at a rural local community hospital. More severely injured trauma patients were identified and transferred to the trauma center more rapidly. Based on experience from the pilot trial between Troms $\varnothing$ and Spitsbergen, a trauma VC network is now being built in 


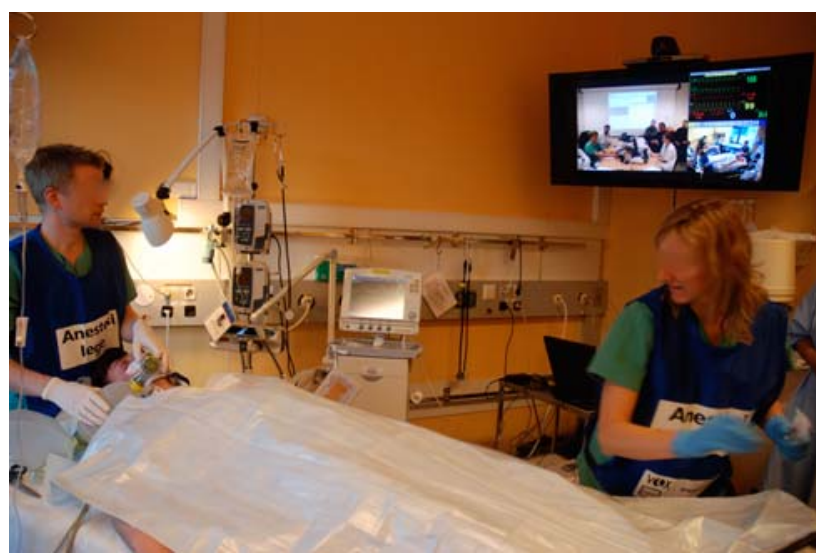

Fig. 3 Trauma mentoring during an Advanced Trauma Life Support (ATLS) exercise. A trauma VC network is established in Northern Norway, linking local hospitals with the University Hospital

North Norway, linking the local hospitals with the university hospital in North Norway (Fig. 3). Other data from University Hospital North Norway show that VC between referring hospitals and a regional neurosurgical service influence patient management and reduce the frequency of patient transfer [36].

Latifi et al. [37] described the telemedicine trauma system at The University Medical Centre and the Arizona Telemedicine Program. These networks are not only used by trauma services but also by all other medical disciplines; they serve close to 1.5 million people. The presence of the trauma surgeon, through $\mathrm{VC}$, has infused confidence in local doctors and communities and is being used to identify knowledge gaps among rural health care providers and the needs for instituting new outreach educational programs. A similar trauma program is presented in an Australian paper [38]. A Virtual Critical Care Unit was created between emergency departments of a district hospital and a metropolitan tertiary hospital. Clinicians reported that the Virtual Critical Care Unit allowed greater support to remote clinicians; however, the specialists reported an increased workload.

New ways to use existing technology are emerging. Recently, a group of neurosurgeons reported new ways to use a simple, relatively cost-effective system using existing mobile phone network services and conventional hand phones with built-in cameras to capture carefully selected images from hard copies of scan images and transfer these images from a hospital without neurosurgical services to a university hospital. This method of consultation proved to be highly convenient and cost-effective [7]. For orthopedic patients, VC via multimedia messaging service (MMS) demonstrated good reliability but poor diagnostic accuracy, which could have major consequences in emergency use [6].

Video-conferencing has been shown to be useful in the management of acute stress disorder and/or posttraumatic stress disorder in the aftermath of traumatic stress exposure. Access to expert assistance can have significant effects on prognosis. The authors discuss the potential benefits and some limitations of early trauma interventions using a VC link to access a civilian population whose access to care is compromised by prevailing conditions [39].

\section{VC for follow-up after surgery}

Video-conferencing is used as an instrument for follow-up of patients during the postoperative period and for outpatient consultation. At our hospital, we have extensive experience in the use of $\mathrm{VC}$ in the follow-up of hemodialysis patients [40] and in dermatology [41, 42].

In addition, a new project has started in the orthopedic department, where a VC line has been established between the university hospital and the district medical center Nordreisa, 155 miles away. In this project, both outpatients and postoperative patients are examined by a district orthopedic nurse under the supervision of an orthopedic consultant located at the university hospital (Fig. 4). This project has now been organized as a randomized controlled trial, where the primary endpoints are cost-effectiveness and patient satisfaction.

Several articles have reported the use of VC in the follow-up of surgical patients. Wallace et al. aimed to compare joint VC between general practitioners, specialists (surgeons), and patients with standard outpatient referral. This randomized controlled trial showed that allocation of patients to virtual outreach consultations was variably associated with increased offers of follow-up appointments according to site and specialty but led to significant increases in patients' satisfaction and substantial reductions in tests and investigations. Efficient operation of such

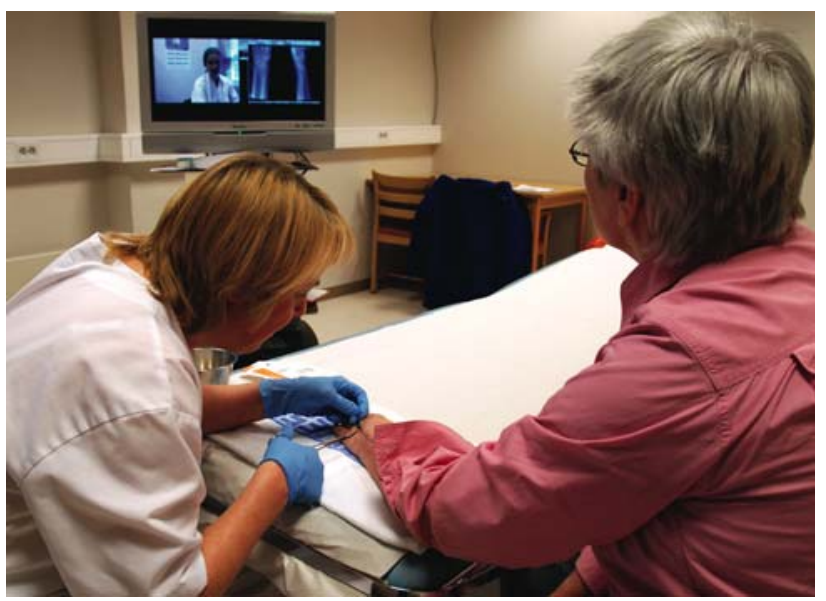

Fig. 4 Video-conference follow-up after surgical treatment. An orthopedic nurse in Nordreisa is performing wound care after instructions given by an orthopedic consultant located at the university hospital 155 miles away 
services requires appropriate selection of patients, significant service reorganization, and provision of logistical support [43].

A study from Finland investigated the use of $\mathrm{VC}$ in the examination of orthopedic outpatients. VC was found to be feasible, and the equipment functioned well technically. The conclusion was that VC between primary and secondary care could be used in the examination of orthopedic patients whenever no demanding imaging technology was needed [44].

Whether VC is cost-effective in the follow-up of surgical patients is still debated. The clinical effectiveness and costs of VC in orthopedics between primary and secondary care were examined in an 8-month prospective comparative study. The general surgery outpatient clinics of two Finnish district hospitals were compared. The direct costs of an outpatient visit were $45 \%$ greater per patient than for a VC. A cost-minimization analysis of the alternative interventions showed a net benefit of EU 2500 in favor of VC [45].

Another Finnish study had similar results. Wider utilization of the $\mathrm{VC}$ equipment for other purposes, or the use of less expensive VC equipment, would make services cost-saving even at relatively short distances [46].

Video-conferencing can be used in almost any medical specialty, although the specialties best suited are those with a high visual component. Wound healing and wound management are thus prime candidates for VC follow-up. Development of a suitable telemedical system in this field could have a significant effect on wound care in the community, tertiary referral patterns, and hospital admission rates $[47,48]$.

\section{Mentoring via VC (surgical telementoring)}

Telementoring - defined by SAGES as real-time interactive teaching of techniques by an expert surgeon to a student not at the same site [4] —was first performed in 1962 by DeBakey [2, 49]. In 1997, Schulam et al. reported the first clinical pilot trial of telementoring [50].

Telementoring has been developed to allow a surgeon at a remote site to offer guidance and assistance to a less experienced surgeon and to reduce the complications associated with surgeon inexperience. In 2000, we established a VC link at 4-6 megabits per second (Mbps) based on the Norwegian Health Network between the Harstad local hospital and the university hospitals in Trondheim and Troms $\varnothing$, 550 miles apart [51]. We wanted to improve cooperation and sharing of competence resources between surgery departments of remote hospitals using advanced applications built on a next-generation Internet technology infrastructure. The first step was to improve the availability and accessibility of the highly specialized competence found at the university hospitals to the rest of the Norwegian laparoscopic surgeons. The project had two goals: to develop standard kits for surgical telementoring (open and laparoscopic) and to test the equipment during regular $\mathrm{VC}$ meetings and during surgical telementoring.

The system was built to handle regular VC from meeting rooms located in the surgical wards at the different hospitals, as well as surgical telementoring of open and laparoscopic surgical procedures from the surgical theater to the meeting rooms. The system in the operating theater was designed to be used without dedicated personnel. The racks with all necessary equipment are plug-and-play and can easily be connected on demand by existing personnel. When connected, the whole unit is remote-controlled by viewing stations participating in the surgery conference. The unit is based on a standard multimedia personal computer running Linux. The remote control includes pan/ zoom of a motorized camera giving overview images of the theater, pan/zoom of a motorized camera mounted in the operation lamp, and switching the video source between the camera and endoscope (Fig. 5). The high-end version viewing station is basically identical to the station in the operating theater; projectors may be connected to reach a larger audience (Fig. 6).

The prototype system supports multipart "surgery conferences" with high quality audio and video channels. In addition to remote control of the video source and motorized cameras, the participants can dynamically control the video channel to give image quality priority over frame rate if needed because of bandwidth constraints. To enhance the cooperative aspect, the cursor of each participant is visible in the video image. The image can also be frozen and saved to disk for further documentation.

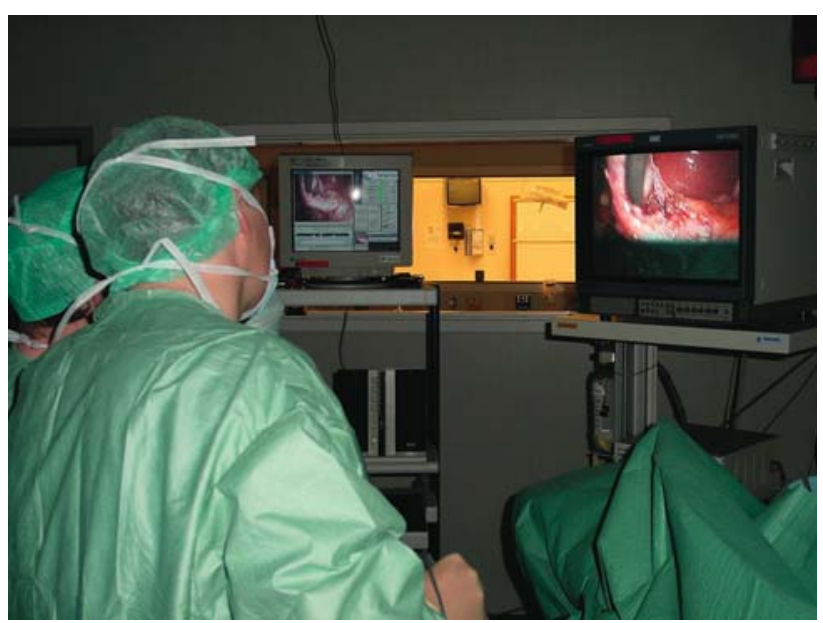

Fig. 5 Surgical telementoring. The system was designed to be used without technical expertise. The racks with all necessary equipment are plug-and-play and can easily be connected on demand by existing personnel 


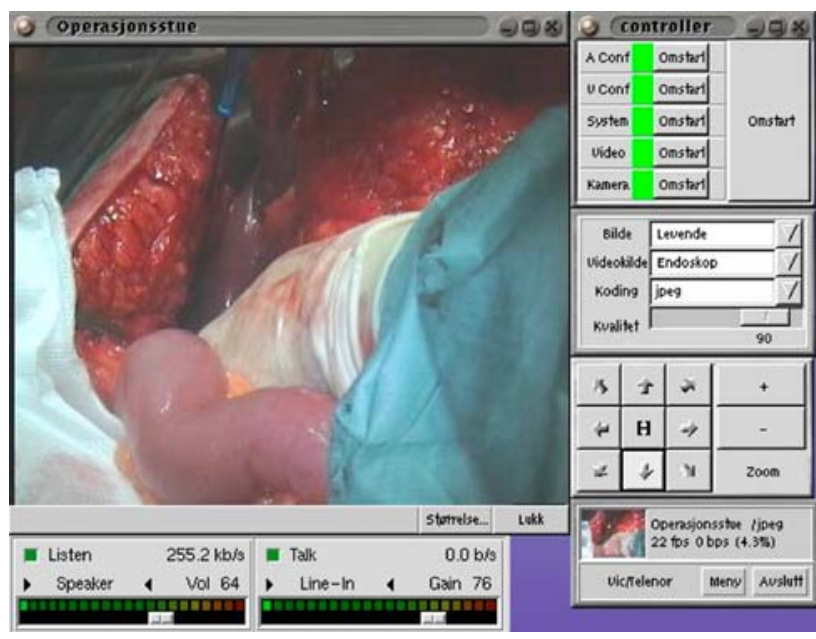

Fig. 6 Surgical telementoring. The remote control includes pan/ zoom of a camera, giving overview images of the operating theater and pan/zoom of a camera mounted in the operation lamp. The system can switch between open and laparoscopic surgical procedures

During the first year, 17 procedures were telementored, mostly laparoscopic cholecystectomies (LCs), between three hospitals participating in the project. In addition, regular VC meetings (lectures) between the surgical departments were conducted.

As a direct consequence of this project, VC surgical lectures were held with participants from France, Italy, Trondheim, and our own institution. Furthermore, we are currently working to develop a VC network (for surgical telementoring, lectures, education, and multidisciplinary meetings) between all the surgical wards in northern Norway.

Several studies of surgical telementoring over large distances have been conducted in various parts of the world. In 1999, a study presented laparoscopic procedures completed through an intercontinental telementoring system and the first telementored laparoscopic procedures performed aboard a naval vessel. The authors concluded that long-distance telementoring was an invaluable tool for providing instantly available expertise during laparoscopic procedures [52].

In 2000, a report on experience from laparoscopic urologic procedures with mentoring between Rome (Italy) and Baltimore (USA) was published [53]. Similar experiments have also been performed by surgeons in the United States and Brazil [54], between the United States and Singapore [55], and inside Italy [56].

Dissemination of new surgical knowledge, skills, and techniques across the wide spectrum of practicing surgeons in the community is often difficult and slow and is even more problematic in rural areas. In an attempt to overcome the barriers that exist, surgeons located at a university hospital have been using broadband Internet and telecommunication systems to provide distance training and mentoring to community surgeons living in remote northern communities of Canada [57].

A study assessed the feasibility, safety, and utility of telementoring as a training tool in LC for higher surgical trainees. The authors concluded that telementoring in LC was a promising tool that might provide objective assessment of a trainee's insight, skill, and progress in operative performance [58].

New applications for VC among surgeons were presented in an article from 2005, describing the use of telementoring for distant teaching and training in endovascular aortic aneurysm repair. This might serve as a model for developing similar projects for teaching other invasive procedures in cardiovascular medicine [59].

A recent study showed that surgical telementoring could be performed without expensive equipment. A cheap, userfriendly telementoring system was used during abdominal, vaginal, and laparoscopic surgery. The authors believe that surgical telementoring deserves attention and that their system could be an ideal tool for studies on telementoring in safe environments [60].

\section{Discussion}

Why does a VC add an important factor during communication between different professions in the surgical community? What kind of information does live transmission of video or digital images add during communication between medical personnel?

In 2004, Maruping and Agarwal [61] presented the "task-technology fit model" as a theoretical model (i.e., "the degree to which technology assists a group in performing its portfolio or task"). According to Maruping and Agarwal [61], the advantages of $\mathrm{VC}$ are the following.

High immediacy in feedback: With VC all communication is conducted in real time; VC provides immediate feedback so the interpretation can be checked.

High symbol variety. Symbol variety defines the availability of multiple cues and language variety that are supported by the medium. VC provides multiple cues such as body language and tone of voice.
Communication
with multiple
participants simultaneously.
High richness. Richness is defined as the ability of information to change understanding within a time interval for tasks requiring social presence.

In a mentor-student situation, a recent study from our own institution by Johnsen and Bolle [8] demonstrated that video calls influenced the information basis and understanding of 
dispatchers. They emphasized visual observation as a way of constructing professional understanding when using $\mathrm{VC}$, which may provide a new basis for dispatcher assistance. VC may also improve the student's compliance. Video-communication can improve the dispatchers' understanding of the students' situation and the assistance they provide [8].

Surgery is, most of all, a visual speciality. Live pictures provide detailed information about anatomic landmarks, giving the mentor instant information about the patient's normal anatomy and pathologic structures. Based on this instant information, the mentor can give advice to the operating surgeon and immediately correct his or her surgical actions. The same aspect is applicable during postoperative follow-up of patients and in trauma care, where visual information regarding clinical signs and symptoms, wound conditions, and radiologic pictures are critical to give the patient the best care. VC in the surgical community has helped deliver better care, especially in rural areas.

Several studies have proven that VC is cost-effective [7, 43-46] in the treatment and follow-up of surgical patients. Furthermore, VC is widely used among trauma surgeons [32, 34-39].

There is a knowledge gap between central and local hospitals [57]. This is even more problematic in rural countries, with community surgeons dispersed in remote corners of a large country and with harsh winters entailing geographic and logistical challenges. Introduction of $\mathrm{VC}$ as an educational tool has led to a decrease in this knowledge gap [10-20, 57].

Until recently, the only proven technique of teaching surgeons new skills were one-site mentoring completed with hands-on course training and conferences. However, because of an overwhelming need for mentors/proctors and supporting evidence in the literature, telementoring is an application whose time has come [50-60, 62-65].

The use of VC has now spread to other areas of the surgical community after decades of surgical telementoring. This adoption of new areas in which to use VC has accelerated after the introduction of the Internet, the decrease in VC equipment costs, and simplification of the technology used.

The purpose of this article was to present our own experiences with $\mathrm{VC}$ as a clinical and educational tool and to perform a review of the topic. As far as we know, this is the first review article of its kind. In our opinion, VC has great potential to change and improve clinical practice among surgeons.

Acknowledgments We thank the entire staff at the Norwegian Centre for Telemedicine for useful comments and reports on the various VC projects. We also acknowledge the press section at the Norwegian Centre for Telemedicine for providing all of the photographs used in this article. Grant support was provided by the Northern Norway Regional Health Authority (Helse Nord RHF).
Open Access This article is distributed under the terms of the Creative Commons Attribution Noncommercial License which permits any noncommercial use, distribution, and reproduction in any medium, provided the original author(s) and source are credited.

\section{References}

1. Aucar JA, Doarn CR, Sargsyan A et al (1998) Use of the Internet for long-term clinical follow-up. Telemed J 4:371-374

2. DeBakey ME (1995) Telemedicine has now come of age. Telemed J 1:3-4

3. Jarvis-Selinger S, Chan E, Payne R, Plohman K, Ho K (2008) Clinical telehealth across the disciplines: lessons learned. Telemed J E Health 14:720-725

4. S.A.G.E.S The Society of American Gastrointestinal and Endoscopic Surgeons (January 2009) Guidelines for the surgical practice of telemedicine; practice/clinical guidelines. http://www. sages.org/publication/id/21

5. International Telecommunication Union (October 2008) http:// www.itu.int/net/home/index.aspx

6. Chandhanayingyong C, Tangtrakulwanich B, Kiriratnikom T (2007) Teleconsultation for emergency orthopaedic patients using the multimedia messaging service via mobile phones. J Telemed Telecare 13:193-196

7. Waran V, Selladurai BM, Bahuri NF et al (2008) Teleconferencing using multimedia messaging service (MMS) for longrange consultation of patients with neurosurgical problems in an acute situation. J Trauma 64:362-365 (discussion 365)

8. Johnsen E, Bolle SR (2008) To see or not to see-better dispatcher-assisted CPR with video-calls? A qualitative study based on simulated trials. Resuscitation 78:320-326

9. Merrell RC, Doarn CR (2008) Is it time for a telemedicine breakthrough? Telemed J E Health 14:505-506

10. Go PM, Payne JH Jr, Satava RM, Rosser JC (1996) Teleconferencing bridges two oceans and shrinks the surgical world. Surg Endosc 10:105-106

11. Olsen J, Nordengen R, Espeland L, Edvardsen H (2006) OrtoPol@r: distance learning in orthodontic postgraduate training_-a pilot project. Norwegian Centre for Telemedicine, Troms $\emptyset$. NST report ISBN 82-92092-76-5

12. Holland AJ, Soundappan SV, Oldmeadow W (2008) Videoconferencing surgical tutorials: bridging the gap. ANZ J Surg 78:297-301

13. Hadley GP, Mars M (2008) Postgraduate medical education in paediatric surgery: videoconferencing - a possible solution for Africa? Pediatr Surg Int 24:223-226

14. Stain SC, Mitchell M, Belue R et al (2005) Objective assessment of videoconferenced lectures in a surgical clerkship. Am J Surg 189:81-84

15. Kingsnorth A, Vranch A, Campbell J (2000) Training for surgeons using digital satellite television and videoconferencing. J Telemed Telecare 6(Suppl 1):S29-S31

16. Demartines N, Mutter D, Vix M et al (2000) Assessment of telemedicine in surgical education and patient care. Ann Surg 231:282-291

17. Lim EC, Seet RC (2008) In-house medical education: redefining tele-education. Teach Learn Med 20:193-195

18. Pradeep PV, Mishra A, Mohanty BN et al (2007) Reinforcement of endocrine surgery training: impact of telemedicine technology in a developing country context. World J Surg 31:1665-1671

19. Binks S, Benger J (2007) Tele-education in emergency care. Emerg Med J 24:782-784

20. Curran VR (2006) Tele-education. J Telemed Telecare 12:57-63 
21. Fleissig A, Jenkins V, Catt S, Followfield L (2006) Multidisciplinary teams in cancer care: are they effective in the UK? Lancet Oncol 7:935-943

22. Demartines N, Mutter D, Marescaux J, Harder F (2000) Preliminary assessment of the value and effect of expert consultation in telemedicine. J Am Coll Surg 190:466-470

23. Norum J, Jordhoy MS (2006) A university oncology department and a remote palliative care unit linked together by email and videoconferencing. J Telemed Telecare 12:92-96

24. Dickson-Witmer D, Petrelli NJ, Witmer DR et al (2008) A statewide community cancer center videoconferencing program. Ann Surg Oncol 15:3058-3064

25. Fielding RG, Macnab M, Swann S et al (2005) Attitudes of breast cancer professionals to conventional and telemedicine-delivered multidisciplinary breast meetings. J Telemed Telecare 11(Suppl 2):S29-S34

26. Delaney G, Jacob S, Iedema R, Winters M, Barton M (2004) Comparison of face-to-face and videoconferenced multidisciplinary clinical meetings. Australas Radiol 48:487-492

27. Kunkler IH, Fielding RG, Brebner J et al (2005) A comprehensive approach for evaluating telemedicine-delivered multidisciplinary breast cancer meetings in southern Scotland. J Telemed Telecare 11(Suppl 1):71-73

28. Kunkler IH, Prescott RJ, Lee RJ et al (2007) TELEMAM: a cluster randomised trial to assess the use of telemedicine in multi-disciplinary breast cancer decision making. Eur J Cancer 43:2506-2514

29. Davison AG, Eraut CD, Haque AS et al (2004) Telemedicine for multidisciplinary lung cancer meetings. $\mathrm{J}$ Telemed Telecare 10:140-143

30. Stalfors J, Bjorholt I, Westin T (2005) A cost analysis of participation via personal attendance versus telemedicine at a head and neck oncology multidisciplinary team meeting. J Telemed Telecare 11:205-210

31. Axford AT, Askill C, Jones AJ (2002) Virtual multidisciplinary teams for cancer care. J Telemed Telecare 8(Suppl 2):3-4

32. Latifi R (2008) Telepresence and telemedicine in trauma and emergency. Stud Health Technol Inform 131:275-280

33. Svalbard Satellite Station (SvalSat) (February 2009) www.ksat. no/Products/Svalsat.htm

34. Hagen O, Bolle SR (2006) Videobased emergency medical interaction. Norwegian National Centre of Telemedicine. Tromsø. NST report ISBN 82-92092-75-7

35. Duchesne JC, Kyle A, Simmons J et al (2008) Impact of telemedicine upon rural trauma care. J Trauma 64:92-97 (discussion 97-98)

36. Stormo A, Sollid S, Stormer J, Ingebrigtsen T (2004) Neurosurgical teleconsultations in northern Norway. J Telemed Telecare 10:135-139

37. Latifi R, Weinstein RS, Porter JM et al (2007) Telemedicine and telepresence for trauma and emergency care management. Scand J Surg 96:281-289

38. Westbrook JI, Coiera EW, Brear M (2008) Impact of an ultrabroadband emergency department telemedicine system on the care of acutely ill patients and clinicians' work. Med J Aust 188:704-708

39. Todder D, Matar M, Kaplan Z (2007) Acute-phase trauma intervention using a videoconference link circumvents compromised access to expert trauma care. Telemed J E Health 13:65-67

40. Rumpsfeld M, Arild E, Norum J, Breivik E (2005) Telemedicine in haemodialysis: a university department and two remote satellites linked together as one common workplace. J Telemed Telecare 11:251-255

41. Moseng D (2000) Teledermatology: experiences from northern Norway. Tidsskr Nor Laegeforen 120:1893-1895

42. Nordal EJ, Moseng D, Kvammen B, Lochen ML (2001) A comparative study of teleconsultations versus face-to-face consultations. J Telemed Telecare 7:257-265
43. Wallace P, Haines A, Harrison R et al (2002) Joint teleconsultations (virtual outreach) versus standard outpatient appointments for patients referred by their general practitioner for a specialist opinion: a randomised trial. Lancet 359:1961-1968

44. Haukipuro K, Ohinmaa A, Winblad I, Linden T, Vuolis S (2000) The feasibility of telemedicine for orthopaedic outpatient clinics: a randomized controlled trial. J Telemed Telecare 6:193-198

45. Harno K, Arajarvi E, Paavola T, Carlson C, Viikinkoski P (2001) Clinical effectiveness and cost analysis of patient referral by videoconferencing in orthopaedics. J Telemed Telecare 7:219-225

46. Ohinmaa A, Vuolio S, Haukipuro K, Winblad I (2002) A costminimization analysis of orthopaedic consultations using videoconferencing in comparison with conventional consulting. J Telemed Telecare 8:283-289

47. Jones SM, Banwell PE, Shakespeare PG (2004) Telemedicine in wound healing. Int Wound $\mathrm{J}$ 1:225-230

48. Wilbright WA, Birke JA, Patout CA, Varnado M, Horswell R (2004) The use of telemedicine in the management of diabetesrelated foot ulceration: a pilot study. Adv Skin Wound Care 17:232-238

49. Merrell RC, Doarn CR (2008) In Memoriam: Michael E. DeBakey, MD. 1908-2008. Telemed J E Health 14:503-504

50. Schulam PG, Docimo SG, Saleh W et al (1997) Telesurgical mentoring: initial clinical experience. Surg Endosc 11:1001-1005

51. Rinde E, Hartviksen G (2000) Telelaparoscopy: user experiences. Telenor ASA, Troms $\varnothing$. Telenor report 93/2000 ISSN 0809-1021

52. Cubano M, Poulose BK, Talamini MA (1999) Long distance telementoring: a novel tool for laparoscopy aboard the USS Abraham Lincoln. Surg Endosc 13:673-678

53. Micali S, Virgili G, Vannozzi E et al (2000) Feasibility of telementoring between Baltimore (USA) and Rome (Italy): the first five cases. J Endourol 14:493-496

54. Rodrigues Netto N, Mitre AI Jr, Lima SV et al (2003) Telementoring between Brazil and the United States: initial experience. J Endourol 17:217-220

55. Lee BR, Png DJ, Liew L et al (2000) Laparoscopic telesurgery between the United States and Singapore. Ann Acad Med Singapore 29:665-668

56. Bruschi M, Micali S, Porpiglia F et al (2005) Laparoscopic telementored adrenalectomy: the Italian experience. Surg Endosc 19:836-840

57. Anvari M (2007) Telesurgery: remote knowledge translation in clinical surgery. World J Surg 31:1545-1550

58. Byrne JP, Mughal MM (2000) Telementoring in laparoscopic cholecystectomy: a useful adjunct in training and assessment of higher surgical trainees. Br J Surg 87:362-373

59. Di Valentino M, Alerci M, Bogen M (2005) Telementoring during endovascular treatment of abdominal aortic aneurysms: a prospective study. J Endovasc Ther 12:200-205

60. Gambadauro P, Magos A (2008) NEST (network enhanced surgical training): a PC-based system for telementoring in gynaecological surgery. Eur J Obstet Gynecol Reprod Biol 139:222225

61. Maruping LM, Agarwal R (2004) Managing team interpersonal processes through technology: a task-technology fit perspective. J Appl Psychol 89:975-990

62. Rafiq A, Moore JA, Zhao X, Doarn CR, Merrell RC (2004) Digital video capture and synchronous consultation in open surgery. Ann Surg 239:567-573

63. Rosser JC Jr, Young SM, Klonsky J (2007) Telementoring: an application whose time has come. Surg Endosc 21:1458-1463

64. Sebajang H, Trudeau P, Dougall A et al (2005) Telementoring: an important enabling tool for the community surgeon. Surg Innov $12: 327-331$

65. Lee BR, Moore R (2000) International telementoring: a feasible method of instruction. World J Urol 18:296-298 